\title{
ERNESTO TRUCCO
}

April 10, 1922 - August, 1970

\section{ObITUARY Notice}

The once very closely knit family of mathematical biologists of the University of Chicago has again suffered an irreparable loss through the death of Dr. Ernesto Trucco, Associate Editor of the Bulletin of Mathematical Biophysics. The actual date of his death is not known exactly. Being a bachelor, he lived alone in an apartment in Lisle, Illinois, not far from the Argonne National Laboratory, where he worked. He was not seen for several days in or around his office. After those several days, on August 25, the police of Lisle broke the door of his apartment. Ernesto Trucco was found to have been dead for already several days. The autopsy showed that death occurred due to a coronary occlusion and must have been instantaneous. He was at least spared a long suffering.

Though originally a Swiss citizen, he was born on April 10, 1922, in Luiro, Italy. He received his elementary and high school education in Milano, Italy. From 1940 to 1945 he studied at the Eidgenossische Technische Hochschule (Swiss Federal Institute of Technology) in Zürich. There he received his physicist's diploma in 1945. After that he worked as Laboratory Assistant in Physics at the University of Berne. Later (1947-1948) he studied at the University of Zürich.

In 1948 he came to the United States and received first his Master's degree in Physics (March 1951) at the University of Chicago. Later he entered the Committee on Mathematical Biology and received his Ph.D. degree in Mathematical Biology in June 1954. From 1954 to 1956 he was a Research Associate in Mathematical Biology at the University of Chicago. From 1956 to 1958 he was Research Associate at the Mental Health Research Institute of the University of Michigan. From 1956 
until his death he was Associate Mathematician, Division of Biological and Medical Research, the Argonne National Laboratory, Argonne, Illinois. He became a naturalized United States citizen in 1960.

Nobody could have been a more loyal and devoted friend than Ernesto Trucco. He was reliability and punctuality personified. A man of unimpeachable integrity, friendly and cooperative, he won the respect of all of his friends.

As a scientist he was a man of unusual talent and great diversity of interests. Besides some earlier publications in physics, many of his publications in mathematical biology are well known to the readers of this Journal. He published also a large number of papers in a number of other periodicals. In the Bulletin alone he published papers on the central nervous system, on imitative behavior, on topological biology, on the information content of graphs, on stochastic theory of mortality, on self-absorbtion of radioactive material, and on mathematical models for cellular systems. His papers on the information content of graphs (1956) formed many years later the basis of the important study on the same subject by A. Mowshowitz (1968). Of late he was working on cell populations, and his last paper on this subject appears in this issue.

He participated in the U.S.-Japan Seminar on Dynamics of Microbial Populations, held in Japan in October 1965. He also chaired a session at the International Congress of Biophysics in Vienna, Austria, in September 1966. From January to March 1969, he was Visiting Professor at the University of Ulm, Germany.

He was also coeditor, with the author of these lines, of the posthumous book, Arms and Insecurity, by the late Lewis F. Richardson (Chicago: Quadrangle Books, 1960).

Besides his numerous papers on the different subjects mentioned above, he also was coauthor with several of his associates of about just as many papers. His name will always live in the annals of mathematical biology. 